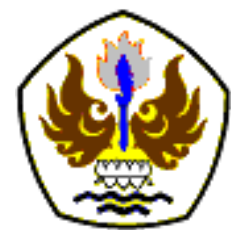

INFOMATEK

Volume 19 Nomor 1 Juni 2017

\title{
KAJIAN TEORITIK PEMILIHAN HEAT PUMP DAN PERHITUNGAN SISTEM SALURAN PADA KANDANG PETERNAKAN AYAM BROILER SISTEM TERTUTUP
}

\author{
Evi Sofia*), Abdurrachim ${ }^{* *}$ \\ *Universitas Nurtanio \\ ${ }^{* *}$ Institut Teknologi Bandung
}

\begin{abstract}
Abstrak: Kebutuhan daging ayam ras broiler (ayam pedaging) cenderung meningkat setiap tahun. Dengan terus meningkatnya konsumsi daging ayam tersebut diperlukan peternak-peternak ayam yang mampu memelihara ayam-ayam pedaging dengan baik. Salah satu penentu untuk menghasilkan ayam-ayam pedaging yang baik adalah sistem perkandangannya. Sistem perkandangan yang baik membutuhkan pengelolaan pengkondisian udara yang tepat. Karena ayam memerlukan temperatur ruangan yang berbeda-beda pada setiap masa pertumbuhannya. Penggunaan Heat Pump sebagai pemanas untuk kandang peternakan ayam broiler memang tidak lazim digunakan. Akan tetapi di beberapa negara penggunaan heat pump dengan fluida kerja air dari tanah (Ground Source Heat pumps/GSHP) banyak digunakan sebagai pemanas kandang ayam. Penggunaan heat pump dengan sistem kompresi uap masih belum ditemui. Kajian ini bertujuan untuk mencoba memanfaatkan Heat pump dengan sistem kompresi uap jika digunakan sebagai pemanas kandang ayam. Kajian diawali dengan menghitung energi yang dibutuhkan kandang, pemilihan heat pump dan perhitungan ducting. Dari hasil kajian ini menunjukkan bahwa penggunaan heat pump sebagai pemanas kandang ayam memungkinkan untuk digunakan.
\end{abstract}

Kata kunci: ducting, heat pump, Ground Source Heat pumps

\section{PENDAHULUAN}

Peningkatan konsumsi daging ayam memerlukan peternak-peternak ayam yang mampu memelihara ayam-ayam pedaging dengan baik. Salah satu penentu untuk menghasilkan ayam-ayam pedaging yang baik adalah sistem perkandangannya. Sistem perkandangan yang baik membutuhkan pengelolaan pengkondisian udara yang tepat. Ayam memerlukan temperatur ruangan yang berbeda-beda pada setiap masa

\footnotetext{
*) e.sofia@ymail.com
}

pertumbuhannya. Umur 0 sampai dengan 14 hari (masa brooding), ayam membutuhkan temperatur lingkungan sekitar $29-34^{\circ} \mathrm{C}$ sedangkan umur 14 sampai dengan panen (kurang lebih 32 hari) ayam memerlukan temperatur udara sekitar $26-27^{\circ} \mathrm{C}$ (Yania dkk. [1]). Pada saat usia brooding adalah usia yang menentukan ayam tersebut akan berkembang dengan baik atau tidak. Akibat dari kebutuhan temperatur pada masa brooding yang bervariasi tersebut dibutuhkan sistem pemanas ruangan. Sistem pemanas ruangan 
yang digunakan biasanya menggunakan bahan bakar gas (LPG). Seiring dengan terus meningkatnya harga gas maka diperlukan alternatif sistem pemanas lain yang lebih efisien. Kajian ini mencoba memberikan alternatif sistem pemanas lain yaitu heat pump dengan sistem kompresi uap.

\section{METODE PENELITIAN}

Tahapan dari kajian ini terdiri dari

1. Menghitung kebutuhan energi kandang.

2. Pemilihan sistem pemanas alternatif berdasarkan kebutuhan energinya (heat pump)

3. Perhitungan ducting.

Kajian dilakukan di peternakan milik Yayasan Pesantren Mangunreja Singaparna Tasimalaya, yang mempunyai temperatur udara berkisar antara $18^{\circ} \mathrm{C}-31^{\circ} \mathrm{C}$. Ayam yang dianalisis berusia satu hari (DOC) sampai 14 hari atau disebut masa brooding. Peternakan ini menggunakan sistem kandang ayam tipe tertutup (closed house) yaitu kandang ayam yang bagian dinding kiri dan kanannya tertutup rapat sedangkan udara yang masuk dan keluar kandang dibantu dengan menggunakan kipas (blower fan atau exhaust fan). Ukuran kandang adalah $100 \mathrm{~m} \times 12 \mathrm{~m} \times$ $2 \mathrm{~m}$ yang dapat menampung sebanyak 15.500 ekor ayam dewasa.

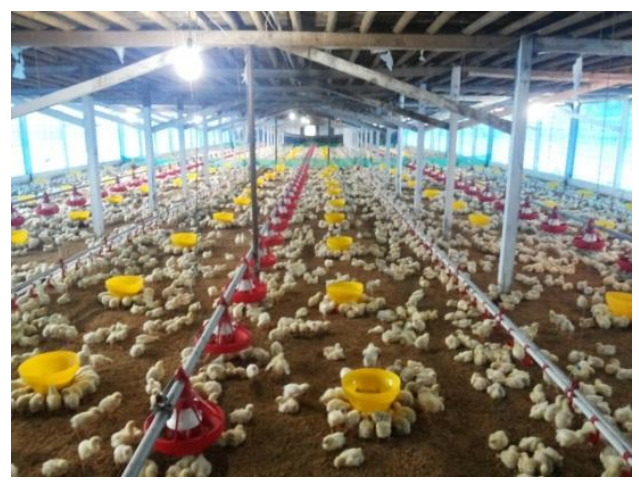

Gambar 1

Gambar bagian dalam kandang ayam

\section{PERHITUNGAN KEBUTUHAN ENERGI}

Perhitungan kebutuhan energi perhari diperoleh dengan terlebih dahulu mendefinisikan sistem dari kandang ayam. Dari sistem tersebut kemudian dihitung kesetimbangan energi dari kandang ayam dengan cara menghitung energi yang masuk dan keluar sistem. Gambar 2 adalah gambar sistem kandang ayam yang akan dianalisis.

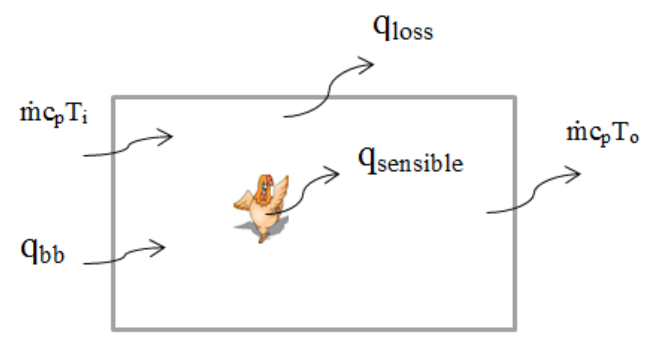

Gambar 2

Sistem Kandang

Dari sistem itu kemudian diperoleh kesetimbangan energinya sebagai berikut (Incropera dkk. [2]): 


$$
\begin{aligned}
& \left(\dot{m} c_{p} \mathrm{~T}\right)_{\text {masuk }}=\left(\dot{m} c_{p} \mathrm{~T}\right)_{\text {keluar }} \\
& \dot{m} c_{p} T_{i}+q_{\text {sensible }}+q_{b b}=\dot{m} c_{p} T_{o}+q_{\text {loss }}
\end{aligned}
$$

\section{Dimana :}

$$
\begin{array}{ll}
\dot{\mathrm{m}} & =\text { laju aliran massa }, \mathrm{kg} / \mathrm{s} \\
\mathrm{C}_{\mathrm{p}} & =\text { Kapasitas jenis udara, } \mathrm{kJ} / \mathrm{kg} \mathrm{K} \\
\mathrm{T}_{\mathrm{i}} & =\text { Temperatur masuk kandang, }{ }^{\circ} \mathrm{C} \\
\mathrm{T}_{\circ} & =\text { Temperatur keluar kandang, }{ }^{\circ} \mathrm{C} \\
\mathrm{q}_{\mathrm{bb}} & =\text { Panas yang dibutuhkan untuk } \\
& \text { pembakaran, } \mathrm{kW} \\
\mathrm{q}_{\text {loss }}= & \text { Panas yang terbuang melalui } \\
& \quad \text { dinding, } \mathrm{kW} \\
\mathrm{q}_{\text {sensible }}= & \text { Panas sensible dari ayam, } \mathrm{kW}
\end{array}
$$

\begin{tabular}{|c|c|c|c|c|c|c|c|}
\hline & 1 & 2 & 3 & 4 & 5 & 6 & 7 \\
\hline Tk,, $\mathrm{K}$ & 307 & 305 & 305 & 305 & 305 & 305 & 305 \\
\hline$T \infty, \mathrm{K}$ & 291 & 295 & 295 & 295 & 295 & 295 & 295 \\
\hline$q \mathrm{q}, \mathrm{kW}$ & 1162 & 1170 & 1170 & 1170 & 1170 & 1756 & 1756 \\
\hline qok,kW & 1210 & 1202 & 1202 & 1202 & 1202 & 1803 & 1803 \\
\hline qloss, $\mathrm{kW}$ & 11 & 10 & 10 & 10 & 10 & 10 & 10 \\
\hline qsensible, $\mathrm{kW}$ & 10 & 13 & 16 & 20 & 24 & 28 & 33 \\
\hline $\mathrm{q}, \mathrm{kW}$ & 49 & 29 & 26 & 22 & 18 & 30 & 25 \\
\hline mdot tabung, $\mathrm{kg} / \mathrm{s}$ & 0,00107 & 0,0006 & 0,0006 & 0,0005 & 0,0004 & 0,0006 & 0,0005 \\
\hline \multirow[t]{2}{*}{ Penggunaan tabung /hari } & 8 & 5 & 4 & 3 & 3 & 5 & 4 \\
\hline & 8 & 9 & 10 & 11 & 12 & 13 & 14 \\
\hline Tk,K & 305 & 304 & 304 & 304 & 304 & 304 & 304 \\
\hline $\mathrm{T} \infty, \mathrm{K}$ & 295 & 295 & 295 & 295 & 295 & 295 & 295 \\
\hline qinh,kW & 1756 & 2341 & 2341 & 2341 & 2926 & 2926 & 2926 \\
\hline qoutk,kW & 1803 & 2404 & 2404 & 2404 & 3005 & 3005 & 3005 \\
\hline qloss, $\mathrm{kW}$ & 10 & 10 & 10 & 10 & 10 & 10 & 10 \\
\hline qsensible, $\mathrm{kW}$ & 38 & 43 & 49 & 55 & 61 & 67 & 74 \\
\hline $\mathrm{q}, \mathrm{kW}$ & 20 & 31 & 25 & 19 & 28 & 22 & 15 \\
\hline mdot tabung, $\mathrm{kg} / \mathrm{s}$ & 0,0004 & 0,0007 & 0,0005 & 0,0004 & 0,0006 & 0,0005 & 0,0003 \\
\hline Penggunaan tabung /hari & 3 & 5 & 4 & 3 & 4 & 3 & 2 \\
\hline
\end{tabular}

Tabel 1 memperlihatkan hasil perhitungan besarnya kebutuhan energi per hari dan penggunaan tabung per hari selama masa brooding.

Tabel 1

Besarnya kebutuhan energi perhari

\section{PEMILIHAN PEMANAS ALTERNATIF (HEAT PUMP)}

Pemilihan heat pump sebagai pengganti pemanas kandang ayam didasarkan pada beberapa pertimbangan antara lain lebih aman, tahan lama, tidak menimbulkan polusi udara, panas yang dihasilkan lebih stabil dan terfokus dan temperaturnya dapat disesuaikan dengan kebutuhan.

Sebagai acuan dalam pemilihan heat pump adalah besarnya kebutuhan bahan bakar maksimum. Dari hasil perhitungan sebelumnya diperoleh kebutuhan bahan bakar maksimum yaitu sebesar $\mathbf{4 9} \mathbf{k W}$. Berdasarkan teori dari siklus kompresi uap (Moran [3]), bahwa besarnya unjuk kerja mesin pendingin atau COP diperlihatkan dalam Persamaan (3) dan (4).

$$
\begin{aligned}
& \mathrm{COP}=\mathrm{q}_{\mathrm{e}} / \mathrm{w}_{\mathrm{k}} \\
& C O P=\frac{q_{c-} W_{k}}{W_{k}}
\end{aligned}
$$

Dimana :

$\mathrm{COP}=$ Unjuk kerja mesin (Coeffisien of

$$
\text { Performance) }
$$

Wk = Kerja/daya kompresor

qc = Kapasitas pemanas

qe = Kapasitas pendinginan

Jika kebutuhan bahan bakar dianggap sama dengan kapasitas pemanas $\left(q_{c}\right)$ maka dengan COP sebesar 3, akan diperoleh besarnya daya kompresor sebesar $13 \mathrm{~kW}$ atau sekitar 17 HP. 


\section{PERHITUNGAN SISTEM SALURAN}

\section{(DUCTING)}

Agar pendistribusian panas lebih merata maka heat pumpdibagi menjadi 3 bagian yaitu 6 HP dinding kiri dan kanan kemudian 5 HP untuk bagian depan dengan pengelolaan sistem saluran (ducting) seperti pada Gambar 3, 4 dan 5.

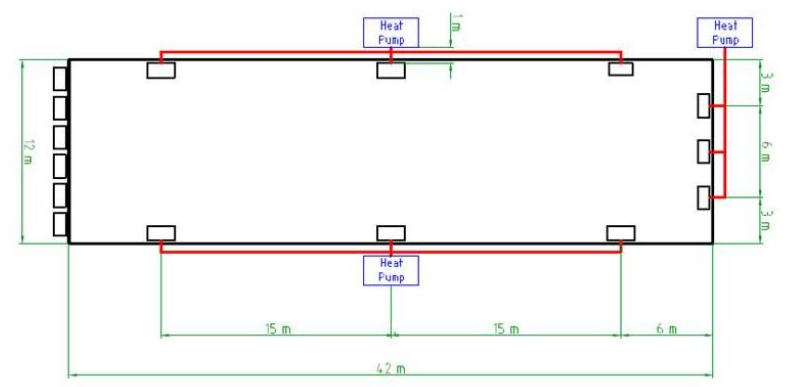

\section{Gambar 3}

Peta sistem saluran

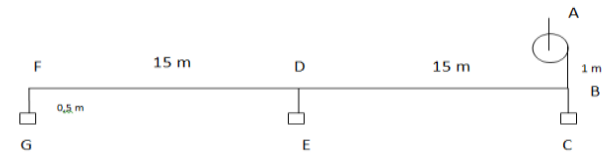

Gambar 4

Layout duct samping

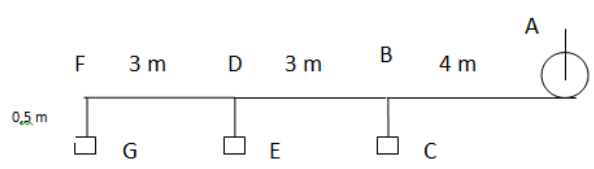

Gambar 5

Layout duct depan
Perhitungan ducting mengacu pada kebutuhan udara dari kandang .Dari buku panduan lengkap ayam disebutkan bahwa kecepatan aliran udara ideal di dalam kandang adalah $120 \mathrm{~m} /$ menit atau sekitar 2 $\mathrm{m} / \mathrm{s}$ [1]. Dari spesifikasi mesin ditentukan bahwa debit dari udara adalah $0,6 \mathrm{~m}^{3} / \mathrm{s}$.

Ada 3 metode dalam mendesain ducting yaitu [3]:

1. Velocity method

2. Equal friction method

3. Optimatimization of duct system

Kajian perhitungan sistem saluran (ducting) dilakukan dengan metode Equal friction, yaitu ducting didesain untuk menghasilkan kehilangan tekanan yang konstan per unit panjang ducting.

Persamaan dasar untuk menghitung Pressure Drop pada saluran lurus dengan penampang lingkaran adalah sebagai berikut :

$\Delta p=f \frac{l}{D_{h}} \frac{V^{2}}{2} \rho$

Dimana :

$\Delta \mathrm{p}=$ Pressure drop, $\mathrm{Pa}$

$\mathrm{f}=$ faktor gesek

$\mathrm{L}=$ panjang, $\mathrm{m}$

$D_{h}=$ Diameter hidrolik saluran, $m$

$\mathrm{V}=$ kecepatan, $\mathrm{m} / \mathrm{s}$

$\rho=$ berat jenis fluida, $\mathrm{kg} / \mathrm{m}^{3}$

Faktor gesekan $f$ adalah fungsi dari rumus Reynold dan kekasaran relatif permukaan pipa 
dimana $\epsilon$ mutlak. Keduanya dipresentasikan karena terdapat faktor gesekan. Maka diperoleh persamaan Colebrook.

$f=\left\{\frac{1}{1.14+2 \log \frac{D}{\varepsilon}-2 \log \left[1+\frac{9.3}{R_{e}}(\varepsilon / D) \sqrt{f}\right]}\right\}^{2}$

Bahan ducting dipilih Galvanized iron/ BJLS (baja lapis seng) dengan kekasaran permukaannya, $\varepsilon=0,15 \mathrm{~mm}[3]$.

Karena bagian samping mempunyai ukuran yang sama maka perhitungan dilakukan hanya pada satu sisi saja.

Dari hasil perhitungan diperoleh dimensi dari duct, yaitu diameter duct karena duct yang akan dipilih berbentuk segiempat maka dimeter duct dianggap sebagai diameter hidrolik $\left(D_{h}\right)$. Dimana diameter hidrolik empat kali luas dibagi perimeter :

$D_{h}=\frac{4(A B)}{2(A+B)}$

Dimana ;

$D_{h}=$ Diameter hidrolik

$\mathrm{A}=$ Tinggi duct

$\mathrm{B}=$ Lebar $d u c t$

B

A

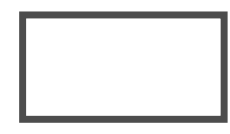

Gambar 6

Dimensi duct
Jika tinggi $\operatorname{duct}(\mathrm{A})$ adalah setengah dari lebar duct (B) maka akan diperoleh dimensi duct seperti terlihat pada Tabel 2 dan 3.

\section{Tabel 2}

Hasil perhitungan mencari dimensi ducting bagian samping

\begin{tabular}{|c|c|c|c|c|}
\hline \multirow{2}{*}{ Bagian } & Dh & A & B & \multirow{2}{*}{ Panjang } \\
\cline { 2 - 4 } & $\mathrm{m}$ & $\mathrm{m}$ & $\mathrm{M}$ & \\
\hline $\mathrm{AB}$ & 0,391 & 0,293 & 0,586 & 1,00 \\
$\mathrm{BC}$ & 0,245 & 0,183 & 0,367 & 0,50 \\
$\mathrm{BD}$ & 0,551 & 0,413 & 0,826 & 15,00 \\
$\mathrm{DE}$ & 0,291 & 0,219 & 0,437 & 0,50 \\
$\mathrm{DF}$ & 0,485 & 0,364 & 0,728 & 15,00 \\
FG & 0,245 & 0,183 & 0,367 & 0,5 \\
\hline
\end{tabular}

\section{Tabel 3}

Hasil perhitungan mencari dimensi ducting bagian depan

\begin{tabular}{|c|c|c|c|c|}
\hline \multirow{2}{*}{ Bagian } & $\mathrm{Dh}$ & $\mathrm{A}$ & $\mathrm{B}$ & \multirow{2}{*}{ Panjang } \\
\cline { 2 - 4 } & $\mathrm{M}$ & $\mathrm{m}$ & $\mathrm{m}$ & \\
\hline $\mathrm{AB}$ & 0,357 & 0,268 & 0,535 & 4,00 \\
$\mathrm{BC}$ & 0,182 & 0,137 & 0,273 & 0,50 \\
$\mathrm{BD}$ & 0,294 & 0,221 & 0,442 & 3,00 \\
$\mathrm{DE}$ & 0,129 & 0,097 & 0,193 & 0,50 \\
$\mathrm{DF}$ & 0,259 & 0,194 & 0,389 & 3,00 \\
FG & 0,182 & 0,137 & 0,273 & 0,5 \\
\hline
\end{tabular}

\section{KESIMPULAN}

1. Dari hasil perhitungan diperoleh bahwa kebutuhan energi maksimum adalah sebesar $49 \mathrm{~kW}$ dan kebutuhan energi maksimum diasumsikan sama dengan kebutuhan bahan bakar.

2. Jika kebutuhan bahan bakar dianggap sama dengan kapasitas pemanas $\left(q_{c}\right)$ maka dengan COP sebesar 3 , akan 
diperoleh besarnya daya kompresor sebesar $13 \mathrm{~kW}$ atau sekitar $17 \mathrm{HP}$.

3. Heat pump dipilih sesuai dengan daya kompresor yang diperoleh dari hasil perhitungan yaitu sebesar $17 \mathrm{HP}$.

4. Agar pendistribusian panas lebih merata maka heat pump dibagi menjadi 3 bagian yaitu $6 \mathrm{HP}$ dinding kiri dan kanan kemudian 5 HP untuk bagian depan.

5. Dari hasil perhitungan diperoleh dimensi duct seperti pada tabel 2 dan tabel 3 .

\section{DAFTAR PUSTAKA}

[1] A. Yania, H. Suhardiyanto, Erizal, \& B. P. Purwanto. 2014. Design of Stocking Density of Broiler for Closed House in Wet Tropical Climates, Media Peternakan.

[2] Incropera, F.,P., Dewitt, D.,P. 1990. Introduction to Heat Transfer $3^{\text {rd }}$ Edition, John Wiley \& Sons, New York.

[3] Moran, M., J. 2002. Introduction to Thermal System Engineering, John Wiley \& Sons. 